\title{
Nutritive value and dry matter yield of Annual Ryegrass 121c
}

\author{
J.P. Marais ${ }^{\text {\#\# }}$ and D.C.W. Goodenough ${ }^{2}$ \\ ${ }^{1}$ KwaZulu-Natal Dept of Agriculture and Environmental Affairs, P Bag X9059, Pietermaritzburg, 3200. \\ ${ }^{2}$ ARC-Range and Forage Institute, Cedara, P.O. Box 1055, Hilton, 3245 \\ \#e-mail:maraisj@cedara.kzntl.gov.za
}

\section{Introduction}

Energy is often the first limiting factor for milk production by dairy cows. The grazing animal derives energy mainly from nonstructural and structural carbohydrates in forages. Animal production from ryegrass can be improved by energy supplementation, but ruminants tend to substitute the grass by supplement, thus depressing forage intake. Furthermore, dry matter intake is also reduced by the high moisture content of annual ryegrass. To overcome these problems, the inherent total nonstructural carbohydrate (TNC) and dry matter (DM) contents of Lolium multiflorum have been increased by breeding and selection. The aim of this study was to compare the dry matter yield and chemical composition of the improved line, 121C, with other cultivars developed at Cedara.

\section{Materials and Methods}

Four replications of line 121C and seven Lolium multiflorum cultivars developed by the ARC-Range and Forage Institute at Cedara were planted in $2 \times 6 \mathrm{~m}$ plots, using a randomized blocks design. The sowing rate was 25 $\mathrm{kg} / \mathrm{ha}$, drilled in rows $150 \mathrm{~mm}$ apart. Each plot received nitrogen at a rate of $50 \mathrm{~kg} / \mathrm{ha}$ after each cut, and potassium at a rate of $50 \mathrm{~kg} / \mathrm{ha}$ after each second cut. Plots were harvested seven times at four-weekly intervals over the growing season. The fresh herbage was weighed and representative samples dried in a forced-draught oven at $80^{\circ} \mathrm{C}$. The samples were milled to pass a $1 \mathrm{~mm}$ screen for subsequent chemical analysis.

\section{Results and Discussion}

Results presented in Figure1a show that the mean DM content over the growing season of selection 121C was much higher (20.8\% on average) than that of the other cultivars. Except for the first cut, when the grass was still in an early growth stage, the DM content of line $121 \mathrm{C}$ never dropped below $180 \mathrm{~g} / \mathrm{kg}$ fresh herbage, which is the critical DM content below which intake is impaired. The mean TNC content of line $121 \mathrm{C}$ was $43.5 \%$ higher than that of the other cultivars (Figure 1b). A high TNC content is often associated with slower growth and a smaller DM yield. Figure 1c shows that the DM yield of selection 121C compared favourably with that of the other cultivars, giving an estimated yield of $12.6 \mathrm{t} / \mathrm{ha}$ over the growing season compared to a mean of $12.3 \mathrm{t} / \mathrm{ha}$ for the other cultivars. In temperate grasses an increase in TNC content is associated with a reduction in the nitrogen content of the grass. Over the growing season the nitrogen content of line $121 \mathrm{C}$ was $13.6 \%$ lower than that of the other cultivars (Figure 1d). The mean nitrogen content of line $121 \mathrm{C}$ was $33.2 \mathrm{~g} / \mathrm{kg} \mathrm{DM} \mathrm{(207} \mathrm{g/kg} \mathrm{crude} \mathrm{protein),}$ which was still in excess of the ruminant's requirements. Low nitrogen concentrations in late-season growth can readily be corrected by nitrogen fertilization.

\section{Conclusion}

The DM yield of line 121C compared well with that of the other cultivars, but it had a much more favourable DM content and nitrogen to energy ratio than the other cultivars Figure1 Composition of annual ryegrass cultivars. 

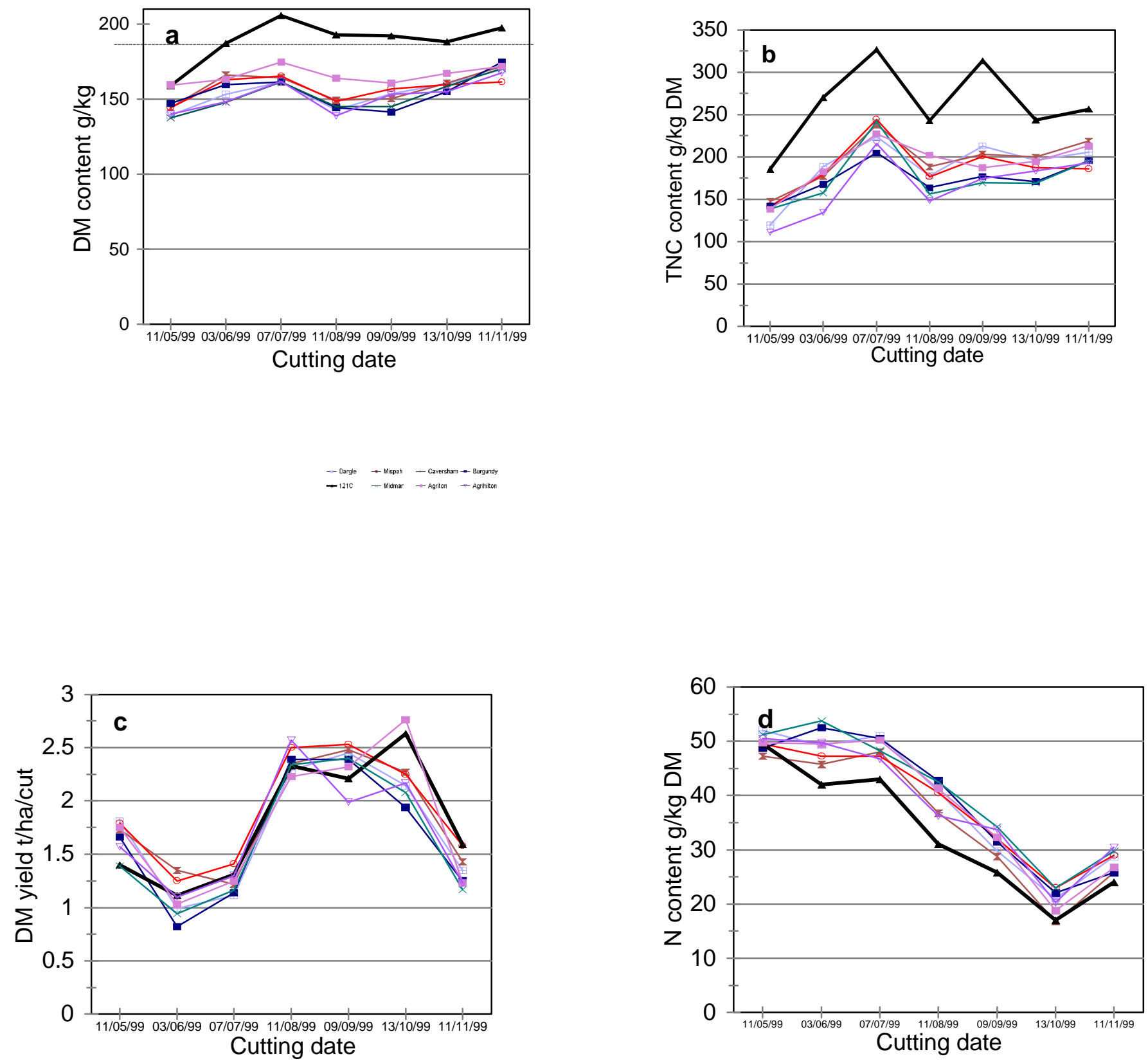

Figure 1 Chemical composition and yields 